\title{
Cytological Differences in the Localization of Glucocorticoid Receptor-Like Immunoreactivity in the Normal and Transplanted Pituitary Pars Intermedia
}

\author{
Fermin C. Iturriza ${ }^{1}$ and César L.A. Gómez Dumm ${ }^{2}$ \\ ${ }^{1}$ Centro de Estudios Endocrinos and ${ }^{2}$ Instituto de Embriolog Ia e Histolog 1a, Facultad de Ciencias Médicas, \\ Universidad Nacional de la Plata, Casilla de Correo 455, 1900 La Plata, Argentina
}

\begin{abstract}
Glucocorticoid receptor-like immunoreactivity (GCRI) was found in the normal pituitary pars intermedia (PI) when immunohistochemistry was used. Since in previous studies we described two kinds of cells in the denervated (grafted) PI, i.e., "light cells" (overactive cells which do not contain detectable melanocytestimulating hormone) and "dark cells" (hypoactive cells which contain the hormone), it was decided to investigate whether different patterns of distribution of the receptors could be detected in the grafted gland when compared with the intact PI. Intact glands showed the receptors located in the nucleus. In transplanted glands, it was observed that light cells showed receptors in both the nuclei and the cytoplasm; on the other hand, dark cells displayed them in the nuclei only, as is the case in all cells of the normal PI.

We had previously interpreted dark cells as dopamine-indifferent, whereas light cells were considered dopamine-sensitive. The changes in the distribution of GCR after denervation by grafting, which only affected the light cells, support the view of other authors that GCR of the pars intermedia are under the influence of dopamine and reinforce our opinion that dark cells are dopamine-indifferent.
\end{abstract}

\footnotetext{
Reprint address:

Dr. Ferm In C. Iturriza

Centro de Estudios Endocrinos

Facultad de Ciencias Médicas

Universidad Nacional de La Plata

Casilla de Correo 455

1900 La Plata

Argentina
}

\section{KEY WORDS}

pituitary gland, pars intermedia, transplants, immunohistochemistry, glucocorticoid receptors, dopamine, melanocyte-stimulating hormone

\section{INTRODUCTION}

So far, only two groups have investigated by immunohistochemistry the presence of glucocorticoid receptors (GCR) in the normal pars intermedia (PI). Each group concluded with opposing results, i.e., Antakly et al. could not determine the existence of GCR /1,2/ whereas Bertini et al. found them /4/; however, authors agree that decentralization of the PI induces the development of such receptors due to the absence of dopaminergic innervation $/ 3,9 /$.

In previous studies $/ 6 /$ we described two kinds of cells in the denervated (grafted) PI, i.e., "light cells" (overactive cells which do not contain detectable melanocyte-stimulating hormone [MSH] and "dark cells" (hypoactive cells which contain the hormone). Thus it was decided to investigate whether different patterns of distribution of the receptors could be detected in the grafted gland when compared with the intact PI.

\section{MATERIALS AND METHODS}

Normal adult male and female SpragueDawley rats were used. Twenty normal pituitaries and nine neurointermediate lobes, which were decentralized by grafting them beneath the kidney capsule for 20 days, were studied. Glands were fixed in Elftman's fluid /5/ for $3 \mathrm{~h}$ and embedded in paraffin. Normal glands were inves- 
tigated only for glucocorticoid receptor-like immunoreactivity (GCRI). Transplants were treated, first, for the demonstration of GCRI and, secondly, for $\alpha$-MSH. Both antigens were detected using the peroxidase-antiperoxidase immunohistochemical procedure (PAP) of Sternberger /10/. 3-Amino-9-ethylcarbazole was used as oxygen acceptor to locate GCRI and 3,3'diaminobenzidine was used for MSH. In order to detect the two antigens separately, sections were stained, photographed and destained in graded alcohol concentrations; antibodies were detached with $3 \mathrm{M}$ ammonium thiocyanate (overnight) /8/. Finally, the same sections were stained for MSH and photographed again. To stain the receptors we used a first monoclonal antibody against Type II GCR generated against rat liver GCR /12/. This antibody, called 1 GR 49/4, was generously supplied by Dr. H.M. Westphal (Institut für Molekularbiologie und Tumorforschung, Marburg, Germany). Details on its preparation and specificity have been published elsewhere /13/. Antibodies were used diluted 1:30-50. MSH was demonstrated with an antiserum kindly supplied by Dr. A. Eberle (Research Department, University Hospital, Basel, Switzerland), directed against the Cterminal portion of the $\alpha$-MSH molecule which fully cross-reacts with diacetylated and deacetylated MSHs showing a very low crossreaction with ACTH (1-39) and analogs (less than $0.03 \%$ ) /7/; antiserum dilution was 1:800.

Both second antibody and PAP solution were purchased at Sigma (St. Louis, USA). The solution to dilute all antibodies was PBS containing $2.5 \%$ Triton $\mathrm{X} 100$.

To test the specificity of the immunohistochemical reaction for GCR the following controls were performed: (a) one of the steps of the immunohistochemical reaction was omitted and, (b) unspecific mouse ascitic fluid was used instead of the primary antibodies.

\section{RESULTS}

By using this antiserum the presence of GCRI in normal rats could be determined in every nucleus of the PI cells (Fig. 1). Cytoplasmic staining was not observed. In grafted glands, nuclei preserved their staining property; nevertheless, a marked difference could be seen after comparing light and dark cell cytoplasm. As described in our previous paper /6/, MSHstaining made it possible to differentiate cells containing granules of the hormone (dark cells) from cells devoid of granules (light cells) (Fig. 3). While light cells showed the presence of GCRI in their cytoplasm after grafting, dark cells remained with a GCRI pattern similar to that of non-transplanted glands (Fig. 2). Controls did not stain at all.

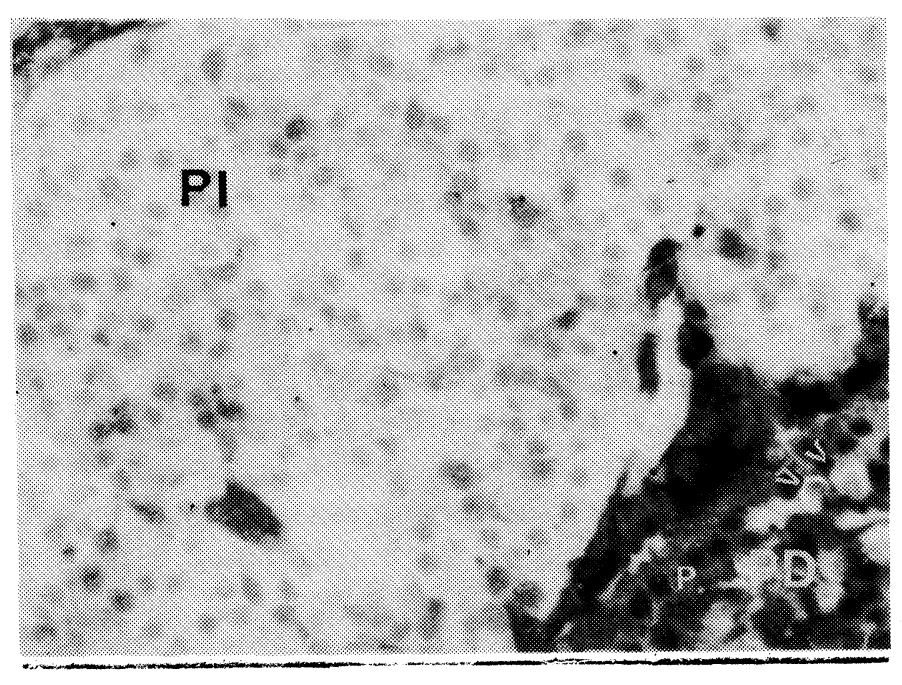

Fig. 1: A section from the pituitary of a normal rat stained for GCR. In the pars intermedia (PI), nuclei, but not cytoplasm, appear positively stained. In the pars distalis (PD) the reaction is stronger and cells displaying either positive $(P)$ or negative (arrow heads) stained cytoplasm are depicted. $\times 150$

\section{DISCUSSION}

Using the same antiserum as the one used by Bertini et al. /4/, we corroborated their findings, namely that the PI actually contains GCRI. As expected, and according to a current view in the field of GCR /11/, they were present in the cell nucleus. Our observations and those of Bertini et al. /4/ are not in accordance with the ones of 


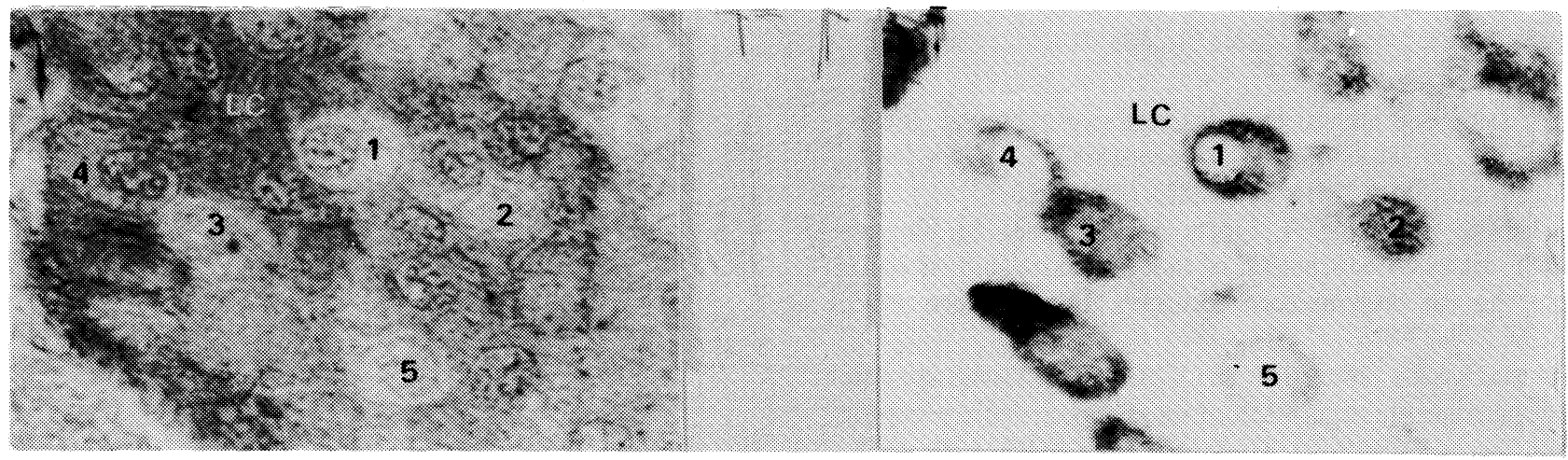

Fig. 2: A section from a transplanted pars intermedia. All cells display nuclear GCRI. Notice that cells marked 1,2, 3, 4 and 5 do not show GCRI in the cytoplasm, whereas other cells, distributed among them, do (LC). $\times 400$

Antakly et al. $/ 1,2 /$, who could not determine the existence of the receptors in the normal PI. The reason for the discrepancy might be that the monoclonal antibodies used by us were more sensitive and specific for GCR. Furthermore, we did not prepare cryostat sections since paraffin sections were suitable for the immunostaining; presumably, we succeeded in the staining either because we used Elftman's fixative /5/ or because the concentration at which the first antibody was used was relatively high.

When Bertini et al. /4/ investigated GCRI with the electron microscope, they observed that some of the receptors were located in the cytoplasm of the normal PI as well. In our light microscope specimens we could not observe such a localization in the normal gland (indeed, electron microscopy should be more sensitive for the reaction products), but we did in light cells of the grafted PI, thus indicating that there was an appreciable increase of receptors in these cells after denervation of the gland. Whether this increase expresses a modification in the wellknown traffic of receptors from the cytoplasm to the nucleus, or corresponds to an increase in receptor synthesis has not yet been ascertained.

We have previously published /6/ that, after cessation of dopamine innervation, cells of the PI differentiate into two kinds, i.e., light cells, which were deprived of MSH storage and showed signs
Fig. 3: The same section as shown in Fig. 2 stained for $\alpha$-MSH. Dark cells $(1,2,3,4,5)$ can be seen. Notice that these cells are the ones that in Fig. 2 do not contain receptors in the cytoplasm; the others, unstained, are light cells (LC) and contain cytoplasm receptors in Fig. 2. $\times 400$

of hyperactivation, and dark cells, containing MSH-secretory granules. Light cells were interpreted as dopamine sensitive, whereas dark cells were considered dopamine indifferent; furthermore, we have suggested /7/ that light cells in the grafts secrete ACTH or ACTH analogs instead of $\mathrm{MSH}$; on the other hand, we thought that dark cells possess little or no secretory activity. The development of GCRI in the cytoplasm of the dopamine sensitive light cells speaks in favor of a dependence between dopamine and GCRI in the PI, as published by other authors, who, however, did not detect two cell kinds in the graft $/ 3,9 /$; moreover, the present observations would reinforce our previous opinion /6/ that dark cells, herein described as not showing appreciable changes in the distribution of GCRI after denervation, are dopamine indifferent.

\section{ACKNOWLEDGEMENTS}

The authors would like to thank Prof. D. Evans for the correction of the manuscript. Thanks are extended to F. Bustos, A. Di Maggio and C. Ferese-Spinelli for their technical assistance. This paper was supported by a grant from the Consejo Nacional de Investigaciones Científicas y Técnicas de la República Argentina (CONICET). 


\section{REFERENCES}

1. Antakly T, Eisen HJ. Immunocytochemical localization of glucocorticoid receptors in target cells. Endocrinology 1984; 115: 1984-1989.

2. Antakly T, Sasaki A, Liotta AS, Palkovits M, Krieger DT. Induced expression of the glucocorticoid receptor in the rat intermediate pituitary lobe. Science 1985; 229: 277-279.

3. Antakly T, Mercille S, Cote JP. Tissue-specific dopaminergic regulation of the glucocorticoid receptor in the rat pituitary. Endocrinology 1987; 120: 15581562.

4. Bertini LT, Westphal HM, de Kloet RE, Kiss JZ. Glucocorticoid receptor immunoreactivity in the rat intermediate lobe. J Neuroendocrinol 1989; 1: 465-471.

5. Elftman $\mathrm{H}$. A chrome-alum fixative for the pituitary. Stain Technol 1957; 32: 25-28.

6. Iturriza FC. Two kinds of cells in grafts of pituitary pars intermedia and their probable dependence on dopamine. Neuroendocrinology 1989; 49: 1-6.

7. Iturriza FC, Eberle AN. Secretion of melanocytestimulating hormone and adrenocorticotrophin from transplanted pituitary pars intermedia in stressed and non-stressed rats. Neuroendocrinology 1989; 49: 610616.

8. Iturriza FC, Gomez Dumm CLA, Bianchi CE. Ammonium thiocyanate for detaching antibodies from histological specimens. Stain Technol (in press).

9. Seger MA, van Eekelen JAM, Kiss JZ. Burbach JPH, de Kloet RE. Stimulation of pro-opiomelanocortin gene expression by glucocorticoids in the denervated rat intermediate pituitary gland. Neuroendocrinology 1988; 47: 350-357.

10. Sternberger LA. Immunocytochemistry. Englewood Cliffs, NJ: Prentice-Hall, 1974.

11. van Eekelen JAM, Kiss JZ, Westphal HM, de Kloet RE. Immunocytochemical study on the intracellular localization of type 2 glucocorticoid receptor in the rat brain. Brain Research 1987; 436: 120-128.

12. Westphal HM, Moldenhauer G, Beato M. Monoclonal antibodies to the rat liver glucocorticoid receptor. EMBO J 1987; 1: 1467-1471.

13. Westphal HM, Mugele K, Beato M, Gehring U. Immunochemical characterization of wild-type and variant glucocorticoid receptors by monoclonal antibodies. EMBO J 1984; 3: 1493-1498. 

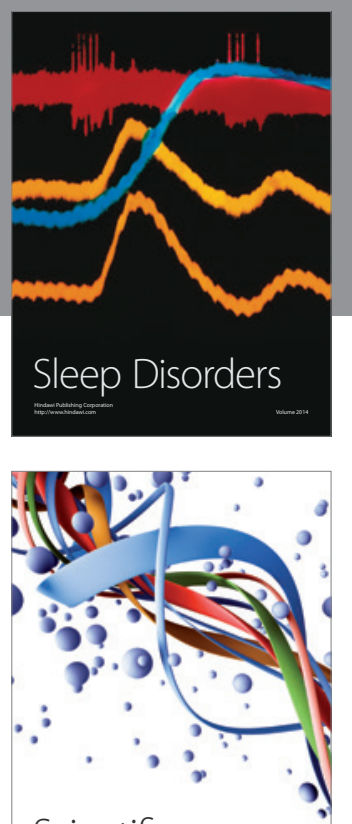

Scientifica
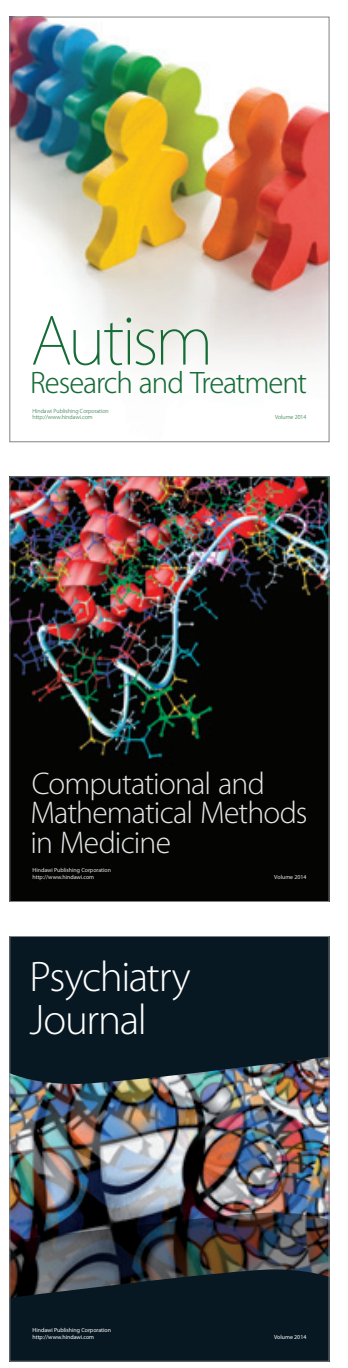
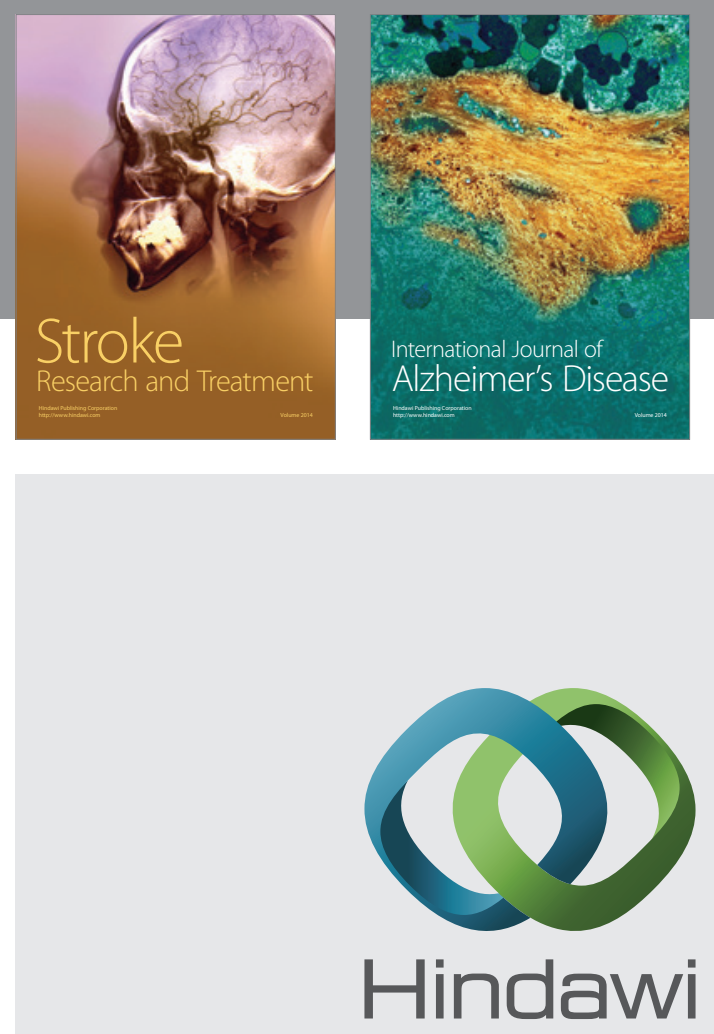

Submit your manuscripts at

http://www.hindawi.com
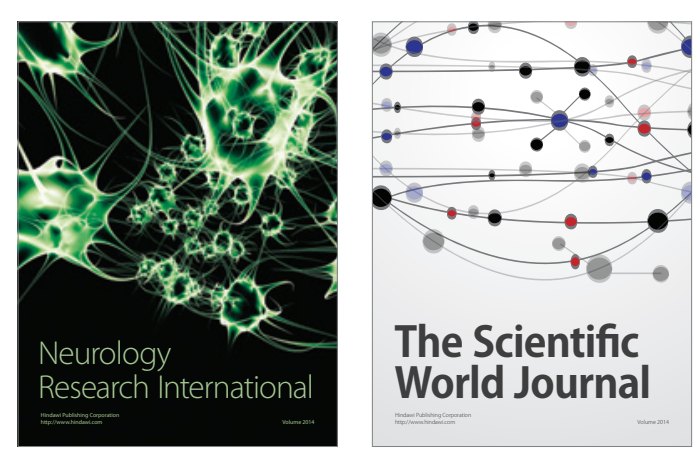

The Scientific World Journal

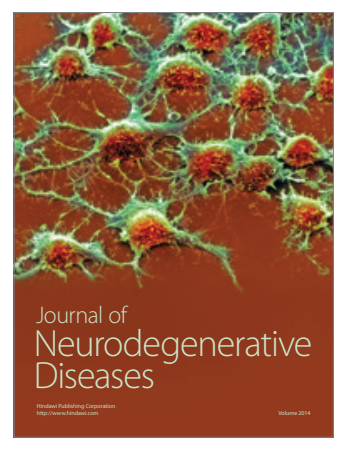

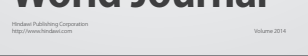

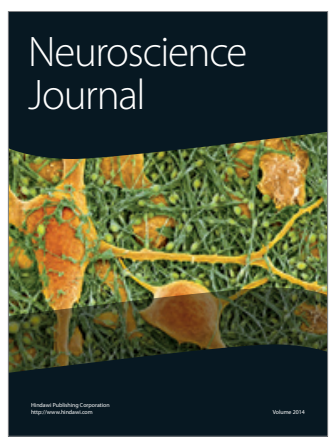

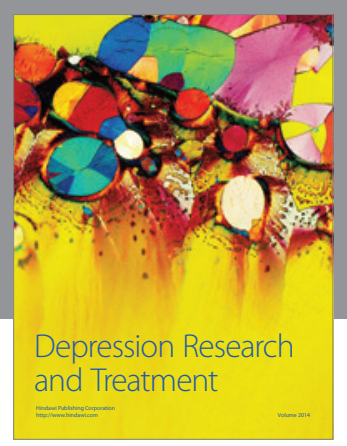
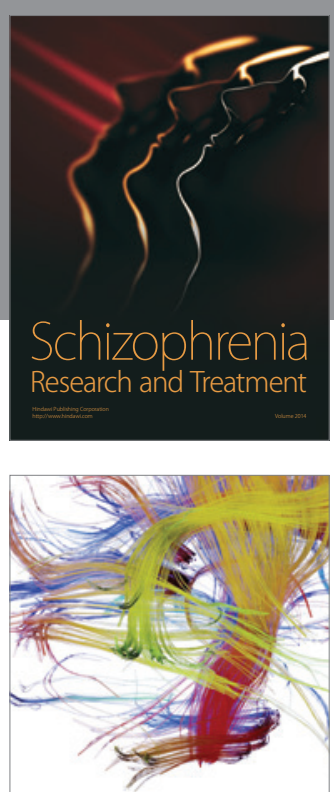

Brain Science

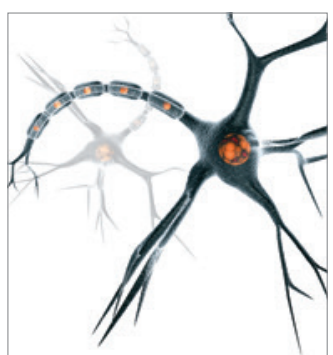

Neural Plasticity
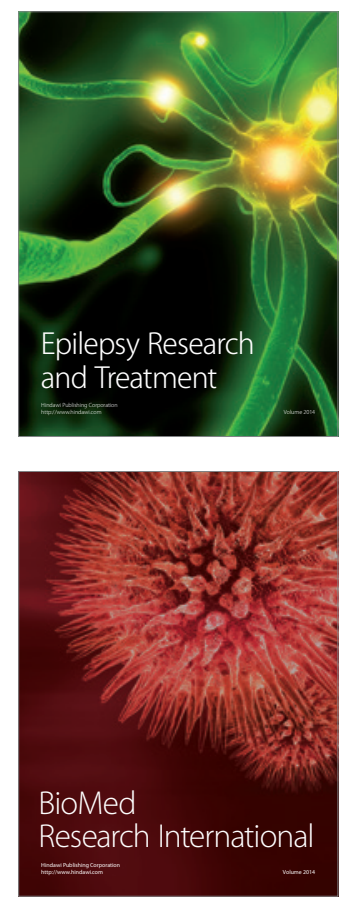

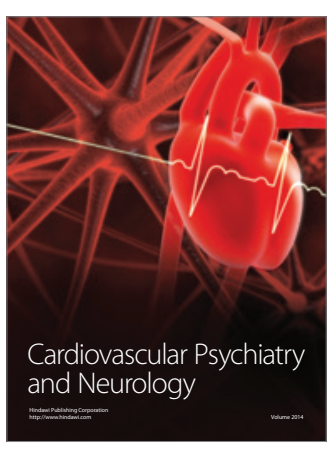

Parkinson's

Disease
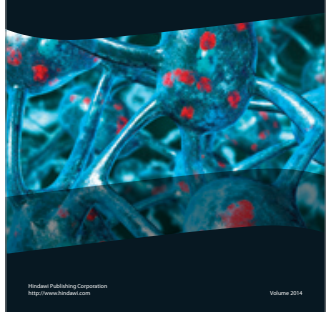